\title{
Factors that Shape the Adolescent's Future Orientation: Analysing Qualitative Data
}

\author{
Matjhabedi E. Mazibuko \\ Vaal University of Technology \\ Private Bag x021, Vanderbij/park, 1911, South Africa \\ chabi.mazibuko@gmail.com \\ D.N. Tlale \\ University of South Africa \\ PO Box 392, Pretoria 0003, South Africa \\ tlaleldn@unisa.ac.za
}

\section{Doi:10.5901/mjss.2014.v5n2p237}

\section{Abstract}

Growing number of studies in social sciences and education domain discuss the value of analysing qualitative data or describe the methodology and data collection processes, but few detail how analysis was carried out. Trustworthiness and credibility of findings from qualitative research depend on the quality of data management, retrieval, and interpretation or identification of meaning. The robustness of data analysis is therefore an important factor in the rigor of qualitative research. This article uses a study of the factors that shape the adolescent's future orientation to illustrate strategies that ensure rigor in qualitative data analysis. The findings in this study indicate adolescent goes through a host of challenges, ranging from the developmental changes to developmental tasks. While negotiating the meaning of his existence and affirming who he really is, the adolescent finds himself at times having to take refuge in substances. Once the adolescent becomes trapped in substance abuse he becomes pre-occupied with how to acquire these substances and everything else takes a back seat, including his school work and his plans about his future.

Keywords: Qualitative research; Data analysis; Data collection; Future orientation; Trustworthiness and credibility.

\section{Introduction}

The main data sources in this research study were interviews, observations and field notes. The following interviews were used: a focus group interview and in-depth individual interviews. The figure below reflects the process of inquiry followed in this study:

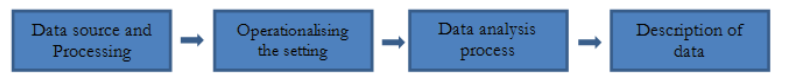

For the purpose of this study the researchers used three data sources to facilitate methodological triangulation. Triangulation is the use of various data gathering methods that can synergise to construct the most accurate and integrated understanding of a phenomenon possible (Denzin \& Lincoln 2005). Observation enabled the researchers to gather a great deal of information through informal naturally occurring conversations during the interviews. Creswell (2012) suggests that the task of an observer is one of listening actively and keenly observing what is going on among the people in a given situation or organization or culture in an effort to more deeply understand it and them.

The interviews were conducted over four days in two schools, namely, Moshate Secondary School and Tharabollo Secondary School. The participants were allowed to express themselves in the language of their choice. The interviews were conducted after permission was granted by the participants for the audio-tape recorder to be used. The importance of the audio-tape was explained and the assurance that the contents of the interviews will be treated as confidential was given. Once the data became saturated, the interviewing of participants was terminated (Gay \& Airasian, 2003). After the interview, each participant was given a chance to listen to the play back of the audio-tape. This was because the participants were promised member checking before any publication of the research content could be made. Member check is the process of asking research participants to tell the researcher whether he had accurately described their experience or agree not to publish anything that the participants do not find truthful. 
Formal arrangements were done with the schools for the interviews to be conducted in quiet venues in the school premises and to ensure that there was no disturbance. The participants started out by sharing with the researchers, the circumstances or situation they wish to be in the five years' time. For the sake of anonymity pseudonyms were used.

\section{Context of the Study}

By explaining how the raw data was collected, it is necessary to explain how the participants were selected and how I gained entry to the setting, as well as to give details of the setting's possible influence on the participants' future orientation.

At Moshate Secondary School focus group interviews were conducted. The data collection methods were explained to the participants. The participants were told that they are free to leave the group if they feel uncomfortable and do not want to be part of the interview permission to conduct the interviews was sought from the participants. At the second school, Tharabollo Secondary School, individual interviews were conducted and each respondent was interviewed privately. The interviews were audio-taped and field notes from direct observation were made. Once the data became saturated, the interviewing of participants was terminated (Gay \& Airasian, 2003).

Both the focus group interviews and the individual interviews were later transcribed verbatim and then translated. Ivankova, Creswell and Stick (2006) refer to the importance of transcribing all raw data into an easily readable form, transcripts, as quickly as possible in an attempt to make sense out of it. The field notes were incorporated into the transcriptions. Each of these was analysed.

\subsection{Operationalising the setting}

Two types of settings are now described. The first setting describes where the focus group interviews took place; the second setting explicates where individual interviews took place. As observations were recorded in both settings, these will be included in the description of the two settings. Johnson, McGowan and Turner (2010) describe observation as a systematic noting and recording of events, behaviour and artifacts in the social setting chosen for study. In this context of the research study, observation entails evaluating the physical setting where the research was conducted, as well as the surroundings within and outside the school yard.

\subsection{Moshate secondary school}

Moshate was established in 1991. The school has an enrolment of eight hundred and sixty nine pupils, of which four hundred and eighty two are girls and the remaining three hundred and eighty seven are boys. The teaching personnel total twenty-six. Moshate Secondary School is situated in the area called Zone Seventeen. Zone Seventeen is the third suburb to be built in Sebokeng Township. The residents of this area are mostly government employees: teachers, nurses, policemen and soldiers, and others who can afford to pay a house bond. On the southern side of the school is an area called Kwa-Masiza, a hostel area, which was meant for migrant male labourers before 1994. In 1994 the KwaMasiza people live below the bread line. On the northern side of the school is an area called Zone fourteen which also caters for those who can afford to pay a bond. Further down on the western side of the school there are RDP houses (RDP are low - cost houses built through the Reconstruction and Development Programme). These houses are for the under-privileged people. Most of the learners in Moshate come from Kwa-Masiza and from RDP houses. Parents form Zone Seventeen and Zone Fourteen send their children to town schools because they can afford to pay for their transport and higher school fees.

There are two gates on the southern side of the school facing Kwa-Masiza, one gate is for motorist and the other for pedestrians. These two gates are the ones used frequently at the school. The third gate is on the western side of the school facing the RDP houses; this gate is also for people walking to school. The school is built on a six hectares plot. It consists of two blocks of double storey buildings which house twenty-four classrooms. From the motorist's gate, one approaches the single storey building which houses the principal's office, the deputy principal office, a staff room, two sick bays, a duplicating room, and male and female staff toilets.

\subsection{Tharabollo secondary school}

The in-depth interviews were conducted at Tharabollo secondary school, which is in Evaton North. This area is about fifty 
kilometers south of Johannesburg. The area was targeted because its inhabitants are a low-income group. The majority of people in this area are unemployed. On the northern side of the school is an area called Orange farm an area where people were given plots to erect houses. As you approach the school, there are several informal settlements where the learners of Tharabollo come from. On the western side of the area is Lake-side and on the eastern side Palm Springs, both areas consist of improved four roomed houses.

Tharabollo secondary school was established in 1993 and was housed at a community centre in Palm Springs. At first the school used a platooning system to accommodate all its learners. The platooning system refers to the system whereby one group of learners start school in the morning and knocks off at midday, and when the first group goes home the second group starts at midday and goes home in the afternoon. In 1998 the school's accommodation problems were solved as it moved to its own building. Tharabollo has an enrolment of one thousand three hundred and fifty three learners. Six hundred and fifty nine girls and six hundred and ninety four are boys. The total number of teachers at this school is thirty-eight including the principal.

Tharabollo has two gates on the southern side, which open into the parking area. The first building from the gates and the parking area is the administration block, which is a single storey building and houses the staff-room, principal's office, deputy and duplicating room. Behind the administration building there are four blocks of triple storey buildings housing a total of thirty-three classrooms.

\subsection{Description of the school's population}

To understand the adolescents who were participants, there are background factors that play an important role in determining how these youngsters view their future. A demographic questionnaire was compiled to elicit information relevant to this study. Some of the background factors that shape the adolescent's future orientation were brought to the fore by interviews. The table below reflects the profile of adolescents in the focus group interviews. Pseudonyms are used to ensure anonymity.

Table 1: Biographical Details of the Participants

\begin{tabular}{|l|c|c|l|c|l|l|l|}
\hline Participant & Sex & Age & Resides With & Resides At & Place Of Work & $\begin{array}{l}\text { Identifyl } \\
\text { Support } \\
\text { System }\end{array}$ & Reason \\
\hline Bernitto & M & 14 & Both parents & Hostel Unit & Unemployed & Friends & Believe in him \\
\hline $\begin{array}{l}\text { Tsietsi } \\
\text { Mahlomola }\end{array}$ & M & 15 & Both parents & Zone 13 & 1 Parent Domestic worker & Friends & Share common interests \\
\hline Larcado & M & 14 & Both parents & Zone 17 & Unemployed & Brother & Trust him \\
\hline Marcus & M & 14 & Mother only & Zone 16 & Domestic worker & Friends & Believe in him \\
\hline Binnyman & M & 15 & Father only & Ext 11 RDP & Unemployed & Friends & Believe in him \\
\hline Finito & M & 14 & Mother only & Hostel Unit & Labourer & Friends & Trust him \\
\hline John Richmond & M & 14 & Both parents & Zone 20 RDP & Unemployed & Brother & Believe in him \\
\hline Teacher & M & 14 & Both parents & Bantu RDP & Unemployed & Brother & Trust him \\
\hline Stones & M & 16 & Both parents & Zone 20 RDP & Mother only domestic worker & Friends & Trust him \\
\hline $\begin{array}{l}\text { Corruption } \\
\text { Question }\end{array}$ & M & 14 & Mother only & Zone 7 & Unemployed & Friends & Believe in him \\
\hline
\end{tabular}

The interviews indicated that $100 \%$ of the respondents think that parental support is lacking at their homes. This lack of support, which the respondents see as an uncaring behaviour on the part of the parents, causes them to turn to friends for support, and as a result they feel compelled to emulate their friends' behaviour for affiliation purposes. The respondents indicated that they will turn to people who believe in them, who trust them and share common interests with them. The interviews also reflected that $60 \%$ of the respondents' parents are unemployed, 30 of the respondents stated that their parents are employed. Although these respondents' parents are employed, they earn little money as indicated by the type of employment they hold.

The data collected show that $40 \%$ of the participants live in disrupted families where the role of parents as nurtures and providers is blurred and blended, where parents are struggling to provide their children with love, nurturance, guidance and support because of single parenting (Seginer, 2009). Marcus, a fourteen-year-old boy has only his mother as a parent, and he is likely to become insecure due to the lack of a father figure with whom to share his experiences and 
identify with.

\section{Data Analysis}

In this study the approach to data analysis is based upon the suggestions of Onwuegbuzie and Combs (2010). Qualitative data analysis is a process consisting of three phases, namely: data reduction, data display and conclusion drawing (Onwuegbuzie \& Combs, 2010). The following steps were implemented: data collected from the interviews were transcribed and translated; observations and field notes were incorporated. The transcriptions were repeatedly read in order to form a holistic understanding and to allow me to return to the transcript to develop the analysis or check it out in detail. Giorgi (2009) encourages close repeated listening to recordings to reveal previously unnoticed recurring features of the organization of talk.

After transcribing all the data, coding was done. Codes are tags or labels for assigning units of meaning to the description or information (Giorgi, 2009). The main themes of the research were identified using coloured pens and open coding was performed in each section. Open coding refers to the process of breaking down, examining, comparing, conceptualizing and categorizing data. The open coding process was approached by analyzing data line by line and lastly the entire document was analysed (Creswell, 2012).

After coding the data, elements that have similar patterns or characteristics were clustered, thus reducing data to ensure a high level of coherent thought. Clustering is a tactic employed to try to understand a phenomenon better by grouping and then conceptualizing objects that have similar patterns or characteristics (Creswell, 2012).

\section{Main Themes that Emerged}

The following framework indicates the main themes identified in the data sources. Each theme will be discussed individually, followed by substantiating quotes. Interpreted data will be compared with existing literature.

Table 2: Main Themes Identified

\begin{tabular}{|l|l|}
\hline Focus Group Interview & Individual Interview \\
\hline Lack of goal orientation & Lack of goal orientation \\
\hline Career orientation & Career orientation \\
\hline Influence of peers & Influence of peers \\
\hline Home environment & Home environment \\
\hline Self esteem & Self esteem \\
\hline
\end{tabular}

\subsection{Lack of goal orientation}

Participants in the study reflected an apparent lack of goal setting tendencies. They lacked motivation and the necessary commitment to their education. The most direct indication as to the level of motivation and commitment is the school attendance rate and beyond this the extent to which they are prepared to make an effort to come early to school. This is more evident in statements such as the following:

"I think I will still be at school....But I think school is a waste of time. School stands in my way of doing things I like. I only go to schools because of my mother. It is a nightmare for me to think that in five years I will still be expected to go to school, when there are so many interesting things going on".

"One other thing that discourages us to like school is that: You'll find that they (teachers) close the gate at 07:50. One teacher will see you approaching the gate and he won't care he will just lock the gate and turn away. He is concerned with his child's future. He is less bothered about our future. When he closes the gate we rejoice! We just go back and relax and smoke."

"When they have (teachers) closed the gate we all contribute something from our pocket money. We can't go home because at home they expect us to be at school. We will then go somewhere where there are lots of trees and roll out our "zolo" (dagga cigar) and go back home at two o'clock".

This confirms the views held by Nurmi (2005) when he states that how adolescents see their future plays an 
important part in their identity formation, which is often defined in terms of exploration of goals and commitments to attaining those goals. The author further points out that by setting future oriented goals, exploring related options, and making commitments, young people direct their own development in their social environment.

Romero (2013) suggests that within this future orientation framework young people set future orientated goals by comparing their present behaviour and their individual motives to their view of the future and their personal perceptions of future possibilities. Nurmi (2005) adds on to say these goals and hopes are then actualized by constructing different plans and strategies.

The mentioned goal setting and goal orientated behaviour is found to be lacking in these adolescents, hence their decisions to stay out of school.

Seginer (2009) maintains that people are likely to embrace a future orientation if they feel that highly valued goals are accessible to them, likewise the belief that a goal is beyond reach may restrict a person to a present orientation. Persistency depends both on the value of a goal and outlook for the future. In support of this notion, Sica (2009) stresses that motivation is required in order to set goals and having knowledge upon which base future expectations is necessary. For example, adolescents who view their future as a replication of their parents' live may be motivated to establish goals that are different. Adolescents may have difficulty envisioning alternative outcomes without knowledge of these outcomes.

In the case of adolescents in this study it seems that lack of motivation, unfair enforcement of school policies and lack of commitment contribute to the adolescents' lack of goal directed behaviour.

\subsection{Career orientation}

It becomes clear that the participants in the study did not hope to get successful employment in the future. The present unemployment rate amongst graduates and matriculants do not provide the youth with a positive view of the future. Occupational trends in the world of work as well as the continued threat posed by HIV and AIDS remained a concern amongst these adolescents, as reflected in the following statements:

"But ma'am some of us will not be able to work because we have started to Subject ourselves to stuff that we are not supposed to be using like, dagga, like alcohol, like drugs, small things like that. These things will prevent us from working".

"You see ma'am I wanted to do electrical engineering, now the school I was attending expelled me, it was a technical school, the whole issue is because I failed grade 9 so what will I become? Nothing."

"I have a problem that prevents me to even think of a future. You see ma'am I am not very strong scholastically I need a lot support. But our teachers do not have time for us. There are so many things that other children master that I do not know. One has come to school to be assisted, but our teachers do not care much for those who struggle.....and where will you work? Nowhere. You'll hang out with ma "auti" (peers) at the car wash and end up without a future".

"Another big problem is HIVIAIDS, that's the thing that prevents people from thinking of their future. You find that one lives in fear of dying, not living for a long time because of Aids, so how do you even plan for a future, when you are going to die? How do you think of career? After all you might die tomorrow what's the use?"

These sentiments expressed by the adolescents in this study concerning their hopelessness towards attaining successful careers are comparable to what Tabachnik, Miller and Relyea (2008) avow about occupational prospects. They declare academic accomplishments are important for navigating the transitions to gainful employment in adulthood. School policies and practices often inhibit efforts of learners to prepare for a successful school to work transition. Systematic school linked barriers facing youths often results in repeated failure and discouragement regarding future occupational prospects.

As indicated earlier in this section the unemployment rate in the country frustrates the youngsters and thwarts their hopes of ever succeeding in the world of work. According to Crockett, Carlo, Wolff and Hope (2011) the adolescents try to impress their sense of outrage at the perceived betrayal by the education system, by becoming involved in activities directed at disrupting teaching. To them education has become ineffective in ensuring a better future with a successful career. People who drop out of school and adopt alternative ways of living become their role models.

Kuhn (2008) posits that the weak labour force attachment, influences individuals' self-efficiency and in turn the extent to which individuals think they can get ahead in life. The author goes on to suggest that discriminatory patterns 
based on gender where employers have a clear preference for black females over black males discourage the youth, and thus cause them to have a foreshortened future orientation about occupation due to the adversities of differential treatment.

Poor academic performance seemed to be related to the respondents' view of their future. Respondents indicated that they are struggling and also that they failed their grades, which could contribute to their poor academic self-concept. As this is related to career orientation it is not unreasonable to suggest that they will evaluate their career orientation in the same way as they evaluate themselves and their level of achievement. Cano, Castillo, Davis, López-Arenas, Vaquero, Thompson and Saldivar (2012) also approve that there is a relationship between learners' evaluations of themselves and their level of academic achievement. Learners who have more positive perceptions of themselves and their abilities are more persistent at school tasks and have a more positive outlook towards future careers, whereas those who have a poor self-concept are more likely to give up when faced with difficult situations (Daviss and Diler, 2012).

In further agreement with the above, Manzi, Vignoles and Regalia (2010) postulates that learners who are constantly faced with failure learn to become helpless. Learners experiencing learned helplessness are likely to engage in attention seeking activities such as being violet with other learners, becoming rebellious or affiliating to groups that abuse substances in order to get a sense of belonging and recognition.

\subsection{Influence of peers}

It was evident that in the absence of parental support and teacher support, the adolescents turned to their peers who provided them not only with support but also with material things, and reinforced their substance abuse behaviour as indicated by the following extracts:
"What can we do then... when others take out dagga and roll it out, we can't ignore it, you can't ignore something that you are using. When it starts burning... when the tree starts burning we gather around it and you no longer think of anything else".
"You know with me I can say, I am really not interested in dagga that much. I was just pushed into it without thinking. What is painful is that you will find that there's nothing to eat at home, the "ma-auti" (friends) will give you something to eat, like they have bought "bunny chow" then after eating they offer you something to smoke, you know some grass then this will help you forget you problems and you will sleep well that day. When you wake up the next day there's still no food so you end up staying with "ma-auti."
"We then stay at home and we will meet with our friends who roll out a "zolo". When you meet with a teacher he'll call you out and say; hey you, you smoking dagga. From there he takes the issue to school and tells the whole class, and then all the girls will be laughing at you."

For adolescents, the transition from primary school to secondary school can involve new academic pressures, conflicts with authorities, difficulty relating to older learners and substance abuse (Manzi, Vignoles \& Regalia, 2010). Some of the issues are attributable to the kind of peers that the adolescent associate with, and the type of neighbourhood he/she lives in.

According to Massey, Gebhardt and Garnefski (2008), the vital role of the adolescents' peer group is the transition from parental dependency to autonomous self-hood. Peer relations become intense and carry a psychological importance during the adolescent period, especially during early adolescence. In the beginning stages of adolescence, the adolescent feels the need to belong to a peer group of her/his choice. Cano, Castillo, Davis, López-Arenas, Vaquero, Thompson and Saldivar (2012) indicate that the desire to identify with one's peer group requires adherence to particular norms, behaviour and role performance that impose conformity. During this stage friendship patterns may go through significant changes due to the larger population from which to choose friends and the increase of extracurricular activities. Moshman (2009) characterises success in interpersonal relationships as more important to many adolescents' self-esteem than academic achievement. Adolescents see friendship with popular peers as a source of status. In some instances being popular might mean being in conflict with authorities. Clearly, peer relationships are a primary task which is important for adolescents' sense of group membership and popularity.

Besides popularity and recognition, the peer group increasingly offers the adolescent a reference point of behaviour. Moshman (2009) states that reference group is a social group that serves as a point of reference in making evaluations and decisions. Peers also take a more active role in shaping behaviour by exerting explicit pressure for conformity, which peaks in adolescence. 


\title{
4.4 Home environment
}

Researchers proposed that the meaning of emotional autonomy and, more specifically, its link to competence, adjustment, interpersonal functioning as well as future orientation can be understood only if considered in the context of the significance of adolescent emotional autonomy. This may differ depending on the quality of the parent-adolescent relationship and the level of stress in the family environment (Cano, Castillo, Davis, López-Arenas, Vaquero, Thompson and Saldivar, 2012).

In this study, poverty, educational negligence and unsupportive parents stood out as contributing factors towards the participants' restricted view of their parents. This is especially true with children's future orientation. Parents can have a profound influence on children's development of a future orientation. The following statements demonstrate this view:

\begin{abstract}
"There's no support from home at all, just yesterday, I was telling my parents that, I am quitting school at the end of this year. You see I told my mom -Tima (Dad) is not working, you don't work too, where am I going to get money for school? My mom said: I will try. She will try, that is not a guarantee and you know what? I will not take the little money she has come, to come back here to school, I can see that we struggle. She says I must come to school but she can't pay my school fees."
\end{abstract}

"Fathers just tell you to read your book: "Read your books." But he will not come to look at what it is you are reading, he will not bother to find out whether there's anything that you don't understand. He will just say read your books."

"At this time my mom or my dad comes in and finds me studying, he won't even look, it's like l'm not there. And I wish he could take a look or even help me or just talk to me about school to give me motivation to continue."

Daviss and Diler (2012) maintain that a negative profile of adjustment and competence would hold true for emotionally autonomous adolescents who perceive their parents as relatively unsupportive and unavailable. This view is witnessed from the participants' account of their hopelessness and incompetence in issues regarding their developmental life domains. Crockett, Carlo, Wolff and Hope (2011) emphasise the importance of parental support by adding that adolescents at greatest risk for internalizing and externalising problems, as well as for low levels of both academic competence and psychological development, were those who described their relationship with their parents as lacking in support.

How parents see the usefulness, relevance and value of schooling affects children's value of education, which results in influencing their perception about the future. Daviss and Diler (2012) say that children may experience failure at school due to parental lack of interest in their education. Moshman (2009) supports this notion by adding that if, for whatever reason, parents do not show appreciation for the school programme; the child will not attach enough value to what is happening in the classroom.

Not only do parents' interests in the children's education influence their future orientation but it also motivates them to set realistic goals which assist them in having something to look forward to. For adolescents, parental unemployment causes increased depression and moodiness, a diminished sense of security and lack of hope for the future (Kuhn, 2008). Parents experiencing economic stress are more pessimistic about their lives and the future of their children, they feel less confident about helping their children prepare for work roles, and are less likely to encourage college attendance (Moshman, 2009).

These parental beliefs and behaviours may dampen the adolescents' expectations and job aspiration. Hinds (1998:82) agree by saying that confidence about his or her future place in the economic order is crucial to an adolescent's sense of hope about the future.

Manzi, Vignoles \& Regalia (2010) acknowledge the importance of environmental factors in understanding differential achievement and the degree to which adolescents possess a comforting or life sustaining, reality based belief that a future exists for themselves and others. Economic stress, inadequate cognitive stimulation in the home, undereducated parents, and parental stress can compromise children's ability to function in school. One aspect of the damage that results from parental unemployment is that it denies the child a positive role model who may help in his or her search for a vocational identity as well as a future orientation.

Within the home environment theme it also became evident that the adolescents' future orientation is negatively affected by parents' alcohol abuse:

"Five years is too far to even think where I will be. There are a lot of things going on around me that make me not to think of five years from now. I don't want to end up like my mother. You see she only thinks of herself and her bottle of 
beer and the rest doesn't exist for her and that includes me."

"...And also parents are an obstacle you know. You'll find that they are drinking, and when they are drunk they fight, you know they disturb you, they make noise, you can't study in such a house! Then when you fail they don't take the blame they shift it to you."

Given the role of parents in significant decisions, it is not surprising that one of the most influential relationships for the adolescents is with his or her parent. The alcoholic parent then fails to maintain this relationship and is also unable to provide the necessary love, support and recognition which an adolescent child required and, constantly embarrassed in front of others; the child identifies with the parent and devalues himself accordingly. In support of this view Husman and Shell (2008) assert that children who have an alcoholic parent are at risk for social maladjustment, self-depreciation, lower self-esteem, alcoholism and a restricted future orientation (Cano, Castillo, Davis, López-Arenas, Vaquero, Thompson and Saldivar, 2012).

Excessive alcohol consumption causes family problems and is associated with family destabilisation. In such families adolescents are deprived of a support system which fosters orientation and which is also an especially important factor in preventing adolescent drinking (Nurmi, 2005). Parents continue to influence decision making skills as the child matures as well as the type of household environment on several levels. Authoritative households appear to be most conducive to fostering adolescent future orientation. Authoritative parents have been described as maintaining an appropriate balance of control and autonomy throughout the child's life, as well as being emotionally and cognitively responsive. These children develop low self-esteem and they have no hope to succeed in life (Nurmi, 2005).

In support of this view, Romero (2013) claims that considerably more alcohol users report poor relationships with parents, broken homes and excessive use by parents of psychoactive drugs. Substance abuse was more likely amongst teenagers whose parents used tobacco and alcohol as well as other substances, than amongst youth whose parents abstained. Parents and by other significant adults who are taking drugs, who serve as role models, affect young children. It is then not unusual to find that these parents, because of a myriad of problems facing them, are pessimistic and hopeless about own future (Romero, 2013).

Santrock (1990:8) takes this view further by signifying that most of the problems of today's youth are not with the youth themselves. The author goes on to point out that what adolescents need is access to a range of legitimate opportunities and to a long-term from adults who care deeply about them.

\subsection{Teachers' support}

Lack of educational support emerged as a contributory factor to the adolescents' restricted future orientation. It was clear that respondents experienced teachers as unapproachable, humiliating and demotivating. The following extracts from the transcripts demonstrate this view:

"Teachers don't support us, they don't motivate us. If you get something wrong in class they'll call you stupid. Your classmates will laugh at you or they (teachers) will call you "mosheshe" (a firework that failed to burn)."

"Sometimes the teachers tell us that they will not talk to us, they will only talk to our books when they say and they start ignoring you, you should know that you have already failed. No matter how hard you try you won't pass."

"Teachers are demotivating. That is very much annoying. They'll tell you that if you don't listen they don't care because they are going to get paid at the end of the month---"

\section{"Some teaches tell us that we are stupid, our heads are made of stones and we are not cut out for mathematics"}

Teachers play an important role in the lives of the learners. Teachers should work on developing their positive perceptions of themselves, others and education if they wish to be a beneficial presence in their learners' lives. Positive perceptions means viewing learners as able, valuable and responsible as well as seeing oneself and education in essentially favourable ways. In viewing learners as able and valuable the teacher instills a sense of hope to the learners, it is not unreasonable to suggest that learners who come into contact with such teachers will value themselves and as a result hold a positive view of the future (Cano, Castillo, Davis, López-Arenas, Vaquero, Thompson and Saldivar, 2012).

It became evident that adolescents in this study were disgruntled because of amongst other things, teachers' unfair practices and uncaring behaviour towards them. The respondents indicated lack of support from the teachers and 
protection from being ridiculed created conflict between them and their peers as well as discouraged them from being enthusiastic about coming to school. O'Reilly, Penn and de Marais (2001:95) points out that adolescent girls feel safe in classroom here they trust that teachers will be fair and also where they trust their confidence will not be betrayed. This is also true for all adolescents; they want teachers to create a safe environment for them to speak in class without fear of ridicule from the teacher or other learners. In the absence of this safety, adolescents withdraw from activities in the classroom and as a result their orientation toward the future. If the school and class atmosphere does not mean a safe learning and social space for the learner, the resulting social maladjustment could cause underachievement and drop out (Hamman, Gosselin, Romano\& Bunuan, 2010).

O'Reilly et al. (2001:95) further state that adolescents want their teachers to believe in them, to believe in their potential to succeed. They expect their teachers not to give up on them just because they failed one test or did poorly on the homework - hey want encouragement. This is also true of the respondents in this study. They indicated that their teachers do not care about them; they felt that they have given up on them. O'Reilly et al. (2001:95) emphasise that teachers should convey high expectations to their learners; they should convey a belief in learners' abilities and their aspirations. With this, teachers will be fostering a positive future orientation in these adolescents.

Woolfolk (1990:5) regards being a motivator as one of the teachers' most important roles, because many decisions a teacher makes have an effect on learner motivation. The respondents reflected that their teachers failed to be motivators. This could have a negative influence on the teacher-learner relationship, which could lead to a negative view of what the future holds for them. They indicated that school loses its meaning to them and they might end up dropping out of school. Not only is a teacher a motivator, but he or she is also a model demonstrating how to think about problems. Woolfolk (1990:7) concurs that if teachers can involve their learners in thinking through various alternative solutions to problems, the learners are more likely to learn that they themselves are capable of problem solving in all kinds of situations.

Teacher support has a strong influence on learners' achievement and emphasises that good teachers should be able to produce a sense of industry, rather that inferiority in their learners. Good teachers know how to recognise special efforts and to encourage special abilities. They also know how to create a setting in which children feel good about themselves and how to handle children to whom school is not important. This suggests that good teachers are able to support learners and assist those whose future seems bleak to find that special ability that can open up the future for her or him. Teachers, more than anyone else, should help learners in the development of their self-concept which in turn will translate into a future oriented learner. This suggests that the attitude and relationship of teacher to learner is of vital importance for effective learning and for the development of future orientation. Derogatory remarks, unsympathetic criticism or merely ignoring the child, as experienced by adolescents in this study, are extremely harmful to the child's self-concept and the meaning he gives to his situation (Hamman, Gosselin, Romano and Bunuan, 2010).

To wrap up, drug taking amongst young people is known to be extensive and is believed to have been increasing. Drug taking usually begins in adolescence and occasionally before. Despite cultural and social differences, much adolescent drug taking displays recognisable communities. The account given by the participants in this study is by no means unusual for drug taking amongst urban youth (Cano, Castillo, Davis, López-Arenas, Vaquero, Thompson and Saldivar, 2012).

\section{Concluding Remarks}

Interviews conducted indicate that substance abuse is related to either restricted or unrealistic positive future orientation. During the in-depth interview one boy saw himself as an economist in five years' time and at the same time expressed that school is a waste of time. Lack of parental love and supervision of the adolescents also contribute in restricting the adolescents' future orientation. Parents and other family members influence future orientation through a unity of mechanisms including modeling, direct socialization of future orientation, setting norms for achievement and communicating expectations.

It became evident that the adolescents in this study lacked good role models. Respondents indicated that they feel like nobody and they already know that they will not succeed and they also know that they will not make it in the world of work. This indicates their parents' situation. Benton and Craib (2011) advice that an individual grows to view themselves as someone who is worthless, based on a self-assessment made in relation to others in his social context. In the present research self-rejection, inner-conflict and hopelessness are revealed in the adolescents' expression of their low and negative future orientation. 


\section{References}

Benton, T. \& Craib, I. (2011) Philosophy of social science: The philosophical foundations of social thought, 2nd ed., Palgrave Macmillan, New York, NY

Cano, M. Á., Castillo, L. G., Davis, M. J., López-Arenas, A., Vaquero, J., Thompson, K. V., \& Saldivar, I. M. (2012). Dynamics of Acculturation, Enculturation, and Ethnic Identity: Influence of Psychocultural Constructs on Conscientiousness and Expectations of Higher Education Among Latinos. International Journal for the Advancement of Counseling, 1-11

Creswell, J. W. (2012). Qualitative inquiry and research design: Choosing among five traditions (3rd ed.). Thousand Oaks, CA: Sage.

Crockett, L.J., Carlo, G., Wolff, J.M., \& Hope, M. (2011). The role of pubertal development, emotional reactivity, and self-regulation in adolescent prosocial behaviours.

Daviss, W.B. \& Diler, R. (2012). Does comorbid depression predictsubsequent adverse life events in youth with AttentionDeficit/Hyperactivity disorder? Journal of Child and Adolescent Psychopharmacology, 22, 65-72.

Denzin, N. K. \& Lincoln, Y. S. (2005) Handbook of Qualitative Research (3rd edition) (Thousand Oaks, Sage).

Giorgi, A. (2009). The descriptive phenomenological method in psychology. Pittsburgh, PA: Duquesne University Press.

Gay, L. R., \& P. Airasian. 2003. Educational research: Competencies for analysis and application, 7th ed. Columbus, OH: Pearson Education.

Hamman, D., Gosselin, K., Romano, J., \& Bunuan, R. (2010). Using possible-selves theory to understand the identity development of new teachers. Teaching and Teacher Education, 26(7), 1349-1361.

Hinds, P 1998: Adolescent Hopefulness in Illness and Health. Advances in Nursing Science, 10 (3), 79-88.

Husman, J., \& Shell, D. F. (2008). Beliefs and perceptions about the future: a measurement of future time perspective. Learning and Individual Differences, 18, 166-175.

Ivankova, N. V., Creswell, J. W., \& Stick, S. L. (2006). Using mixed-methods sequential explanatory design: From theory to practice. Field Methods, 18, 3-20.

Johnson, R. B., McGowan, M. W., \& Turner, L. A. (2010). Grounded theory in practice: Is it inherently a mixed method?Research in the Schools, 17(2), 65-78

Kuhn, D. (2008). Formal operations from a twenty-first century perspective. Human Development, 51(1), 48-55.

Manzi, C., Vignoles, V. L., \& Regalia, C. (2010). Accommodating a new identity: Possible selves, identity change and well-being across two life-transitions. European Journal of Social Psychology, 40(6), 970-984.

Massey, E.K., Gebhardt, W.A., \& Garnefski, N. (2008). Adolescent goal content and pursuit: review of the literature from the past 16 years. Developmental Review, 28(4), 421-460.

Moshman, D. (2009). Adolescence. In U. Muller, J. Carpendale, \& L. Smith (Eds.) The Cambridge Companion to PIAGET (255-269). Cambridge University Press: New York City.

Nurmi, J. E. (2005). Thinking about and acting upon the future. In A. Strathman \& J. Joireman (Eds.), Understanding behaviour in the context of time (pp. 31-57). New Jersey: Lawrence Erlbaum Associates Publishers.

Onwuegbuzie, A. J., \& Combs, J. P. (2010). Emergent data analysis techniques in mixed methods research: A synthesis. In A. Tashakkori \& C. Teddlie (Eds.), Sage handbook of mixed methods in social \& behavioral research (2nd ed., pp. 397-430). Thousand Oaks, CA: Sage.

O'Reilly, P; Penn, E M \& de Marais, K 2001; Educating Young Adolescent Girls. London: Lawrence Erlbaum Associates

Patton, M. Q. (2002) Qualitative Research \& Evaluation Methods (3rd Edition) (Thousands Oaks, Sage).

Romero, A. (2013)"Educational Future Orientation of Middle School Latino Students". Counseling and Psychological Services Dissertations. Paper 87

Santrock, J W 1990: Adolescence (fourth edition). Dallas: WMC Brown Publishers.

Seginer, R. (2009). Future orientation: Developmental and ecological perspectives. New York: Springer.

Sica, L. (2009). Adolescents in different contexts: The exploration of identity through possible selves. Cognition, Brain, Behaviour: An Interdisciplinary Journal, 13(3), 221-252.

Tabachnik, S. E., Miller, R. B., \& Relyea, G. E. (2008). The relationships among students' future oriented goals and subgoals, perceived task instrumentality, and task-oriented self-regulation strategies in an academic environment. Journal of Educational Psychology, 100, 629-642.

Woolfolk, A E 1990: Educational Psychology (Fourth Edition). Boston: Allyn and Beacon.

Zhang, L., Karabenick, S. A., Maruno, S., \& Laurermann, F. (2011). Academic delay of gratification and children's study time allocation as a function of proximity to consequential academic goals. Learning and Instruction, 21(1), 77-94. 